\title{
Differential expression of matrix metalloproteinases and miRNAs in the metastasis of oral squamous cell carcinoma
}

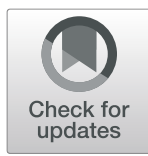

\author{
Zhen-Hu Ren ${ }^{\dagger}$, Kun Wu ${ }^{\dagger}$, Rong Yang, Zhe-Qi Liu and Wei Cao ${ }^{*}$
}

\begin{abstract}
Background: Our study aimed to reveal the regulatory mechanisms of miRNAs and matrix metalloproteinases (MMPs) in oral squamous cell carcinoma (OSCC).

Methods: The mRNA and miRNA expression profiles of six metastatic tumour samples, six nonmetastatic tumour samples, and six normal tissue samples were used for microarray analysis. Moreover, the important genes and miRNAs were validated by published profiles in Oncomine and by qRT-PCR.

Results: MMP7, MMP13, and MMP10 were upregulated, and MMP12 and MMP9 were downregulated in metastatic tumours compared with nonmetastatic tumours. MMP7 was regulated by miR-4697-5p and miR-7109-5p. MMP7 and MMP13 were upregulated in OSCC samples compared with normal samples in Oncomine. Moreover, qRT-PCR revealed that the expression of miR-7109-5p and miR-34b was decreased in metastatic tumours compared with nonmetastatic tumours.
\end{abstract}

Conclusions: Our study suggested that miR-7109-5p and miR-34b might play important roles in the metastasis of OSCC by regulating MMP7 and MMP13 expression, respectively.

Keywords: Oral squamous cell carcinoma, Matrix metalloproteinases, Microarray, Metastatic tumour, miRNAs

\section{Background}

Oral squamous cell carcinoma (OSCC) is one of the most common malignancies of the head and neck region in the world $[1,2]$. OSCC is particularly risky and is usually discovered when the cancer has metastasized to the lymph nodes of the neck since it progresses without producing pain or symptoms that might be readily recognized by the patients in its early stages [3]. Although surgical resection followed by postoperative radiotherapy and/or chemotherapy has made considerable treatment progress, the 5-year overall survival rate of OSCC patients still remains poor due to the common neighbouring tissue invasion and neck lymph node metastasis [46]. Moreover, though many research groups have made

\footnotetext{
*Correspondence: caowei9hospital@163.com

The abstract of this study has not been presented at any meetings regarding the research on the title page.

${ }^{\dagger}$ Zhen-Hu Ren and Kun Wu contributed equally to this work.

Department of Oral and Maxillofacial-Head and Neck Oncology, Ninth

People's Hospital, Shanghai Jiao Tong University School of Medicine, No. 639 Zhizaoju Road, Shanghai 200011, China
}

great efforts to study OSCC pathogenesis, the underlying mechanisms of OSCC tumourigenesis and development have not been fully elucidated. Therefore, further studies focusing on the molecular mechanisms of OSCC are still urgently needed to improve early diagnosis, targeted therapy and prognosis.

Matrix metalloproteinases (MMPs) are a family of highly homologous extracellular zinc- and calciumdependent endopeptidases with enzymatic activity and are capable of degrading many components from either the extracellular matrix (ECM) or basement membrane [7]. Studies have shown that MMPs are involved in numerous physiopathological processes, such as tissue remodelling, embryonic development, mammary involution, bone reabsorption, and wound healing $[8,9]$. MMPs induced by both tumour cells and surrounding stromal cells are related to various processes associated with tumour cell proliferation, angiogenesis, neighbouring invasion and remote metastasis due to their ability to degrade ECM and alter cell migration [10, 11]. Increased

(c) The Author(s). 2020 Open Access This article is distributed under the terms of the Creative Commons Attribution 4.0 International License (http://creativecommons.org/licenses/by/4.0/), which permits unrestricted use, distribution, and reproduction in any medium, provided you give appropriate credit to the original author(s) and the source, provide a link to the Creative Commons license, and indicate if changes were made. The Creative Commons Public Domain Dedication waiver (http://creativecommons.org/publicdomain/zero/1.0/) applies to the data made available in this article, unless otherwise stated. 
levels of one or several MMPs have been found in most human cancers [12]. Overexpressed MMP-2 and MMP9 are involved in the invasion process of OSCC, and MMP-9 is related to the poor prognosis of OSCC patients without neck node metastasis [13]. Significantly higher MMP-1, MMP-2, MMP-3, MMP-7, MMP-9, MMP-10, MMP-11, and MMP-13 levels were found in tumours compared with normal mucosa, and MMP-9 might be useful for evaluating the malignant potential of head and neck squamous cell carcinoma [14]. It has also been reported that CXCR4 might promote OSCC cell migration and invasion by regulating MMP9 and MMP13 expression to activate the ERK signalling pathway [15]. Overall, increasing evidence has suggested that MMPs play critical roles in OSCC progression.

MicroRNAs (miRNAs) are a class of short noncoding RNAs that regulate the levels of posttranscriptional mRNAs by anchoring to the target sites on mRNA sequences in a complementary base-pairing manner [16, 17]. It has been reported that miR-222 inhibits OSCC cell invasion via the downregulation of MMP1 expression [18]. Moreover, miR-29a may play an inhibiting role in the progression of OSCC by negatively regulating MMP2 expression [19]. These findings provide important clues for potential therapeutic targets and approaches in the future. However, the miRNA regulatory mechanisms of MMP expression in OSCC metastasis remain unclear. Thus, the elucidation of aberrantly expressed MMPs and the related miRNA regulatory mechanisms in OSCC progression is critical.

In the present study, we aimed to reveal the possible regulatory mechanisms related to miRNAs and MMPs involved in the OSCC metastatic process. Samples collected from patients with nonmetastatic or metastatic tumours, as well as normal controls, were used for highthroughput mRNA and miRNA microarray analysis. The selected important markers involved in the metastatic process were also validated by experiments in another cohort of OSCC patients.

\section{Methods}

\section{Patients and clinical tissue samples}

Twenty-seven OSCC patients (14 with nonmetastatic tumours and 13 with metastatic tumours) were enrolled in our retrospective study. The tumours were diagnosed and staged according to the 8th edition of the AJCC/ UICC cancer staging manual [20]. All patients underwent en bloc excision with primary tumour excision combined with neck dissection (bilateral neck dissection was performed if the tumour crossed the midline) in our hospital (Oral and Maxillofacial-Head and Neck Oncology Department, Ninth People's Hospital, Shanghai Jiao Tong University School of Medicine) between October 2016 and March 2017. The primary tumour site of metastatic OSCC, primary tumour site of nonmetastatic OSCC and paired normal oral mucosa outside the tumour $2 \mathrm{~cm}$ away belonged to the same anatomical site as the primary tumour and were collected during surgery (all tissues were cut with a steel knife and immediately snap-frozen in liquid nitrogen). The nonmetastatic patients did not have occult lymph node metastasis discovered postoperatively. The clinical and pathological characteristics of the enrolled patients are listed in Tables 1 and 2. The tumour samples collected from six metastatic OSCC patients (No. 1-6), as well as the tumour and paired adjacent normal tissue samples collected from six nonmetastatic OSCC patients (No. 712), were used for the microarray assay. The tumour samples from another eight nonmetastatic OSCC patients (No. 13-20) and seven metastatic OSCC patients (No. 21-27) were obtained for further experimental validation.

The retrospective study was approved by the Scientific Research Projects Approval Determination of Independent Ethics Committee of Shanghai Ninth People's Hospital affiliated with Shanghai Jiao Tong University. Informed consent was obtained from all subjects before the samples were collected during surgery.

\section{Total RNA isolation and microarray processing}

Total RNA was extracted from the metastatic tumour, nonmetastatic tumour and normal control tissue samples using TRIzol reagent (Invitrogen, USA) according to the manufacturer's protocol. Afterwards, the extracted RNA was purified by a Total Tissue RNA Purification Kit (Qiagen Inc., Valencia, CA, USA). The RNA concentrations were measured by a NanoDrop 2000 spectrophotometer (Thermo Scientific, Wilmington, DE, USA). Denaturing gel electrophoresis was used to examine the purity and integrity of the total RNA extracted from the tissue samples.

The qualified total RNA was used to synthetize firststrand cDNA using a cDNA synthesis kit (TIANGEN, China), followed by fluorescent labelling with Agilent's Low Input Quick Amp WT Labeling kit (Agilent Technologies, USA) according to the manufacturer's instructions. The labelled cDNA was purified with an RNeasy Mini kit (Qiagen, Germany) and hybridized onto the Agilent Human SurePrint G3 Human GE $8 \times 60 \mathrm{k}$ v16 microarray chip (Agilent Technologies, USA) [21] by Shanghai OE Biotech Company (Shanghai, China). Total RNA was also used for the miRNA microarray experiment. The miRNA molecules in total RNA were labelled with the Agilent miRNA labeling reagent and hybridized onto the Agilent Human SurePrint G3 $8 \times 60 \mathrm{k}$ v16 miRNA microarray chip (Agilent Technologies, USA) according to the manufacturer's protocol. After hybridization, the samples were scanned by an Agilent 
Table 1 Clinical characteristic of the oral squamous cell carcinoma (OSCC) patients used for microarray assay and qRT-PCR

\begin{tabular}{|c|c|c|c|c|c|c|}
\hline NO. & Tumor statue & Age range (years) & Site & Clinical stage & TNM classification & Application \\
\hline 1 & Nonmetastatic & $40-49$ & Tongue & $\|$ & T2NOMO & Microarray assay \\
\hline 2 & Nonmetastatic & $60-69$ & Oral floor & III & T3NOMO & Microarray assay \\
\hline 3 & Nonmetastatic & $40-49$ & Tongue & $\|$ & T2NOMO & Microarray assay \\
\hline 4 & Nonmetastatic & $60-69$ & Gingiva & $\|$ & T2NOMO & Microarray assay \\
\hline 5 & Nonmetastatic & $40-49$ & Tongue & IV & T4NOMO & Microarray assay \\
\hline 6 & Nonmetastatic & $50-59$ & Buccal mucosa & III & T3NOMO & Microarray assay \\
\hline 7 & Metastatic & $50-59$ & Tongue & III & T2N1M0 & Microarray assay \\
\hline 8 & Metastatic & $60-69$ & Tongue & IV & $\mathrm{T} 2 \mathrm{~N} 2 \mathrm{MO}$ & Microarray assay \\
\hline 9 & Metastatic & $40-49$ & Tongue & IV & T1N2M0 & Microarray assay \\
\hline 10 & Metastatic & $60-69$ & Tongue & IV & $\mathrm{T} 2 \mathrm{~N} 2 \mathrm{MO}$ & Microarray assay \\
\hline 11 & Metastatic & $50-59$ & Tongue & IV & $\mathrm{T} 2 \mathrm{~N} 2 \mathrm{MO}$ & Microarray assay \\
\hline 12 & Metastatic & $50-59$ & Buccal mucosa & IV & T1N2M0 & Microarray assay \\
\hline 13 & Nonmetastatic & $50-59$ & Tongue & $\|$ & $\mathrm{T} 2 \mathrm{NOMO}$ & qRT-PCR \\
\hline 14 & Nonmetastatic & $40-49$ & Tongue & $\|$ & T2NOMO & qRT-PCR \\
\hline 15 & Nonmetastatic & $60-69$ & Buccal mucosa & $\|$ & T2NOMO & qRT-PCR \\
\hline 16 & Nonmetastatic & $40-49$ & Gingiva & $\|$ & T2NOMO & qRT-PCR \\
\hline 17 & Nonmetastatic & $30-39$ & Tongue & $\|$ & $\mathrm{T} 2 \mathrm{NOMO}$ & qRT-PCR \\
\hline 18 & Nonmetastatic & $60-69$ & Gingiva & III & T3NOMO & qRT-PCR \\
\hline 19 & Nonmetastatic & $70-79$ & Tongue & III & T3NOMO & qRT-PCR \\
\hline 20 & Nonmetastatic & $50-59$ & Tongue & IV & T4NOMO & qRT-PCR \\
\hline 21 & Metastatic & $50-59$ & Buccal mucosa & IV & T1N2M0 & qRT-PCR \\
\hline 22 & Metastatic & $70-79$ & Tongue & IV & $\mathrm{T} 2 \mathrm{~N} 2 \mathrm{M} 0$ & qRT-PCR \\
\hline 23 & Metastatic & $60-69$ & Tongue & IV & T2N2M0 & qRT-PCR \\
\hline 24 & Metastatic & $60-69$ & Tongue & IV & $\mathrm{T} 2 \mathrm{~N} 2 \mathrm{MO}$ & qRT-PCR \\
\hline 25 & Metastatic & $50-59$ & Oral floor & IV & T1N2M0 & qRT-PCR \\
\hline 26 & Metastatic & $50-59$ & Buccal mucosa & IV & T4N1M0 & qRT-PCR \\
\hline 27 & Metastatic & $40-49$ & Tongue & IV & T3N1M0 & qRT-PCR \\
\hline
\end{tabular}

TNM tumor, node metastasis

Table 2 Basic information was compared between the two groups

\begin{tabular}{llll}
\hline Group & nonmetastatic & metastatic & $P$ \\
\hline Age(y) & 55.7 & 57.9 & 0.468 \\
Gender & & & 0.157 \\
Man & 12 & 13 & \\
$\quad$ Woman & 2 & 0 & $\mathbf{0 . 0 1 2}$ \\
Clinical stage & & & \\
II & 8 & 0 & \\
III & 4 & 1 & 0.163 \\
IV & 2 & 12 & \\
Tumor site & & & \\
Tongue & 8 & 9 & \\
Buccal & 2 & 3 & \\
Gingiva & 3 & 0 & \\
Oral floor & 1 & 1 & \\
\hline
\end{tabular}

Microarray Scanner (Agilent Technologies, USA), and raw data were obtained by using feature extraction software (Agilent Technologies, USA). GeneSpring GX 12.6 software (Agilent Technologies, USA) was used to normalize the obtained raw data.

\section{Microarray data analysis}

The limma (Linear Models for Microarray Analysis) [22] package in $\mathrm{R}$ was used to perform differential expression analysis. The thresholds for differentially expressed genes (DEGs) and differentially expressed miRNAs (DEmiRNAs) were set as $\mid \log _{2}$ fold-change (FC) $\mid>0.5$ and $p$-value $<0.05$. Moreover, the expression values of screened MMP-related DEGs and DE-miRNAs were hierarchically clustered by the pheatmap package [23] in $R$ based on the encyclopaedia of distances [24] to observe the differences in expression levels intuitively. 


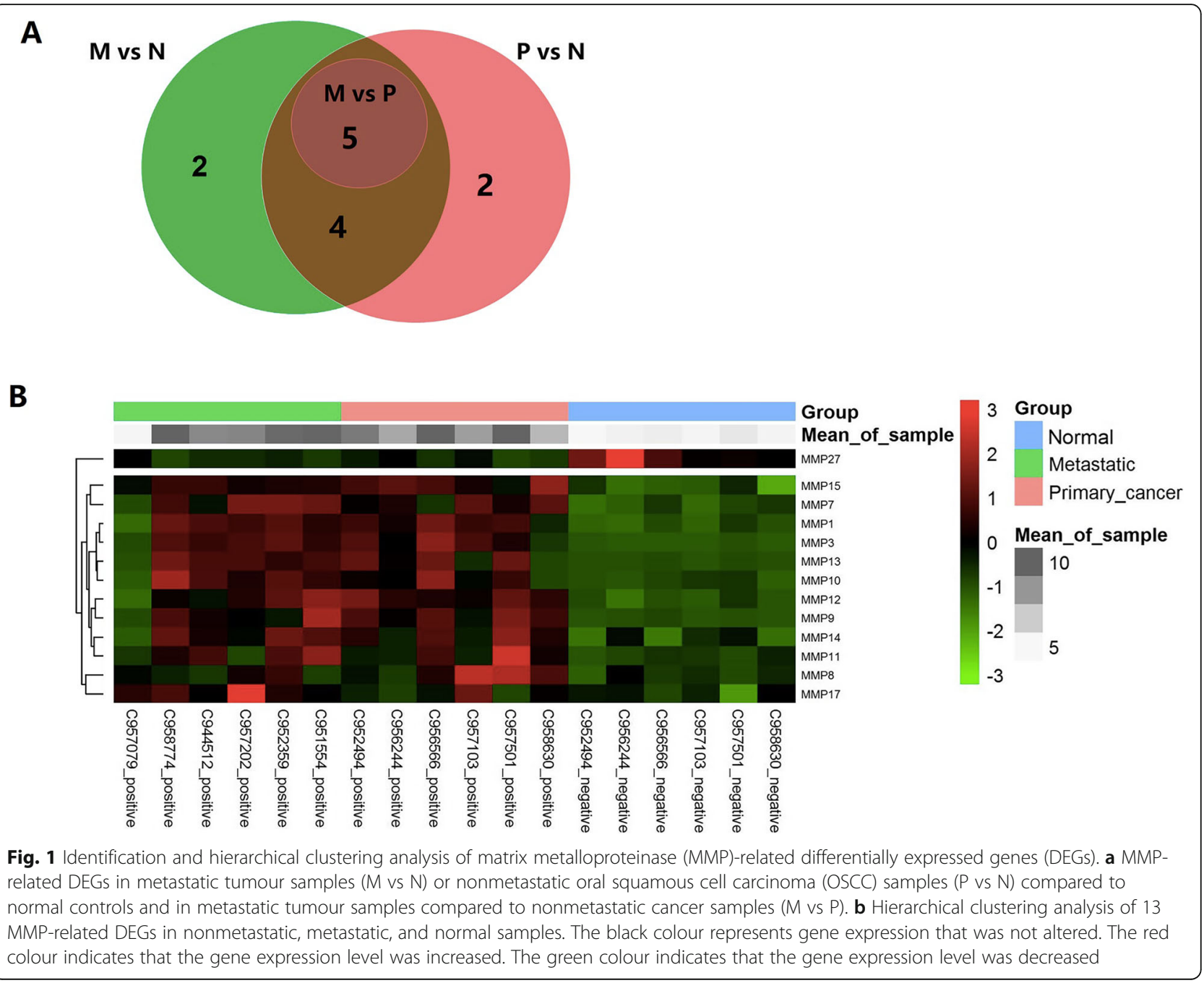

The target genes of the differentially regulated miRNAs were predicted by TargetScan (http://www.targetscan.org/vert_71/) [25], miRDB (http://mirdb.org) [26], miRTarBase (http://mirtarbase.mbc.nctu.edu.tw/) [27], and TarBase (http://www.microrna.gr/tarbase) [28]. The miRNA-mRNA regulatory relationships involved with MMPs were selected to construct the MMP-related regulatory network via Cytoscape (http://www.cytoscape. org/) [29]. Furthermore, we used Oncomine (http:// www.oncomine.org) to reveal the expression of important genes in the available microarray data comparing OSCCsamples with normal samples.

\section{Gene ontology (GO) functional and pathway enrichment analysis}

The GO functions in terms of the biological process (BP), molecular function (MF), and cellular component (CC) categories for the MMP-related DEGs and target genes of DE-miRNAs were enriched through the Database for Annotation, Visualization and Integrated
Discovery (DAVID) [30]. The potential pathways of these MMP-related DEGs and target genes were also revealed by Kyoto Encyclopedia of Genes and Genomes (KEGG) and Orthology-Based Annotation System (KOBAS) [31]. The cutoff criterion was set as $p$-value $<$ 0.05 .

\section{Quantitative real-time RT-PCR (qRT-PCR)}

Total RNA was extracted with TRIzol Reagent (Invitrogen, USA), and cDNA was synthesized using the miRcute Plus miRNA First-Strand cDNA Synthesis Kit (TIANGEN, China). All real-time qPCR reactions were performed using an ABI StepOne Real-time PCR system (Life Technologies, USA) and the miRcute Plus miRNA qPCR kit (TIANGEN, China). The threshold cycle calculation of each miRNA was performed with SPSS software version 17.0 (SPSS Inc., Chicago, IL, USA). The samples with undetermined $\mathrm{Ct}$ values $(\mathrm{Ct}>40)$ for the control were excluded from analysis. The fold change was assessed using the $2^{-\Delta \Delta C t}$ method. The relative 


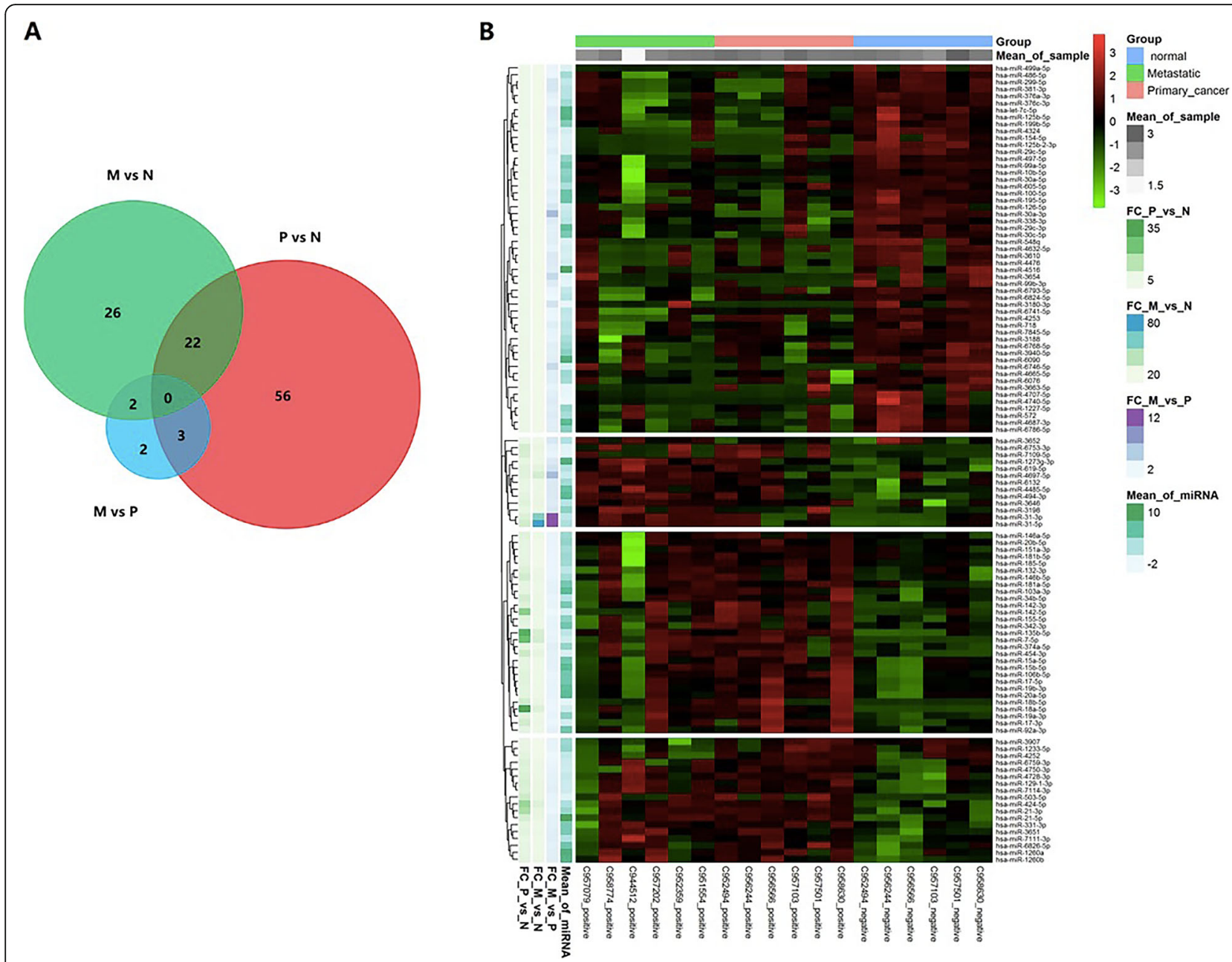

Fig. 2 Identification and hierarchical clustering analysis of differentially expressed miRNAs (DE-miRNAs). a The DE-miRNAs in metastatic tumour samples (M vs N) or nonmetastatic samples ( $P$ vs N) compared to normal controls and in metastatic tumour samples compared to nonmetastatic cancer samples (M vs P). b Hierarchical clustering analysis of 111 DE-miRNAs in nonmetastatic, metastatic, and normal samples. The black colour indicates that miRNA expression was not altered. The red colour indicates that the miRNA expression level was increased. The green colour indicates that the miRNA expression level was decreased

expression of the miRNAs was normalized using U6 as an endogenous control. Two-sample t test was used to compare the normalized expression levels between the two groups. A $p$-value $<0.05$ was considered a statistically significant difference.

\section{Results}

\section{Identification of MMP-related DEGs and DE-miRNAs}

We screened the MMP-related DEGs in metastatic tumour samples ( $\mathrm{M}$ vs $\mathrm{N}$ ) or nonmetastatic tumour samples ( $\mathrm{P}$ vs $\mathrm{N}$ ) compared to normal controls and in metastatic tumour samples compared to nonmetastatic cancer samples ( $\mathrm{M}$ vs P) (Fig. 1a). A total of 13 MMPrelated DEGs were identified. Ten MMP family members (MMP12, MMP15, MMP1, MMP9, MMP7, MMP3, $M M P 14, M M P 13, M M P 10$, and $M M P 8)$ were upregulated and one was downregulated (MMP27) in nonmetastatic tumour samples compared with normal controls. Ten MMP family members (MMP12, MMP1, MMP9, MMP7, MMP3, MMP14, MMP13, MMP17, $M M P 10$, and $M M P 11)$ were upregulated and one was downregulated (MMP27) in metastatic tumour samples compared with normal controls. $M M P 7, M M P 13$, and $M M P 10$ were significantly upregulated, while $M M P 12$ and $M M P 9$ were downregulated in metastatic tumour samples compared with nonmetastatic tumour samples. Hierarchical clustering analysis showed that the gene expression profiles were significantly different among nonmetastatic tumour samples, metastatic tumour samples, and normal tissues (Fig. 1) (details in the Additional file 1).

According to the differential expression analysis, a total of 111 DE-miRNAs were identified. There were 81 significantly dysregulated miRNAs (35 downregulated 
Table 3 The Gene Ontology (GO) functional enrichment analysis in terms of biology process (BP), cellular component (CC), molecular function (MF) for the MMP-related differentially expressed genes (DEGs)

\begin{tabular}{|c|c|c|c|c|c|}
\hline Category & GO_ID & Term & $\begin{array}{l}P \\
\text { value }\end{array}$ & Count & Genes \\
\hline \multirow[t]{10}{*}{$\overline{\mathrm{BP}}$} & $\begin{array}{l}\text { GO: } \\
0030574\end{array}$ & collagen catabolic process & $\begin{array}{l}2.583 e- \\
24\end{array}$ & 11 & $\begin{array}{l}\text { MMP7, MMP14, MMP13, MMP1, MMP3, MMP8, MMP9, MMP12, } \\
\text { MMP10, MMP11, MMP15 }\end{array}$ \\
\hline & $\begin{array}{l}\text { GO: } \\
0032963\end{array}$ & collagen metabolic process & $\begin{array}{l}2.654 \mathrm{e}- \\
22\end{array}$ & 11 & $\begin{array}{l}\text { MMP7, MMP14, MMP13, MMP1, MMP3, MMP8, MMP9, MMP12, } \\
\text { MMP10, MMP11, MMP15 }\end{array}$ \\
\hline & $\begin{array}{l}\text { GO: } \\
0044259\end{array}$ & $\begin{array}{l}\text { multicellular organismal macromolecule } \\
\text { metabolic process }\end{array}$ & $\begin{array}{l}4.247 e- \\
22\end{array}$ & 11 & $\begin{array}{l}\text { MMP7, MMP14, MMP13, MMP1, MMP3, MMP8, MMP9, MMP12, } \\
\text { MMP11, MMP10, MMP15 }\end{array}$ \\
\hline & $\begin{array}{l}\text { GO: } \\
0022617\end{array}$ & extracellular matrix disassembly & $\begin{array}{l}1.031 e^{-} \\
21\end{array}$ & 11 & $\begin{array}{l}\text { MMP7, MMP13, MMP3, MMP12, MMP10, MMP15, MMP14, MMP1, } \\
\text { MMP8, MMP9, MMP11 }\end{array}$ \\
\hline & $\begin{array}{l}\text { GO: } \\
0044236\end{array}$ & multicellular organismal metabolic process & $\begin{array}{l}1.445 \mathrm{e}- \\
21\end{array}$ & 11 & $\begin{array}{l}\text { MMP7, MMP13, MMP3, MMP12, MMP10, MMP15, MMP14, MMP1, } \\
\text { MMP8, MMP9, MMP11 }\end{array}$ \\
\hline & $\begin{array}{l}\text { GO: } \\
0030198\end{array}$ & extracellular matrix organization & $\begin{array}{l}1.668 \mathrm{e}- \\
16\end{array}$ & 11 & $\begin{array}{l}\text { MMP7, MMP12, MMP10, MMP15, MMP14, MMP8, MMP13, MMP3, } \\
\text { MMP1, MMP9, MMP11 }\end{array}$ \\
\hline & $\begin{array}{l}\text { GO: } \\
0043062\end{array}$ & extracellular structure organization & $\begin{array}{l}1.720 \mathrm{e}- \\
16\end{array}$ & 11 & $\begin{array}{l}\text { MMP7, MMP12, MMP10, MMP15, MMP14, MMP8, MMP13, MMP3, } \\
\text { MMP1, MMP9, MMP11 }\end{array}$ \\
\hline & $\begin{array}{l}\text { GO: } \\
0006508\end{array}$ & proteolysis & $\begin{array}{l}3.499 \mathrm{e}- \\
11\end{array}$ & 12 & $\begin{array}{l}\text { MMP7, MMP12, MMP10, MMP14, MMP17, MMP15, MMP13, MMP3, } \\
\text { MMP8, MMP9, MMP11, MMP1 }\end{array}$ \\
\hline & $\begin{array}{l}\text { GO: } \\
0035987\end{array}$ & endodermal cell differentiation & $\begin{array}{l}3.661 e^{-} \\
10\end{array}$ & 4 & MMP9, MMP14, MMP15, MMP8 \\
\hline & $\begin{array}{l}\text { GO: } \\
0001706\end{array}$ & endoderm formation & $\begin{array}{l}1.064 \mathrm{e}- \\
09\end{array}$ & 4 & MMP9, MMP14, MMP15, MMP8 \\
\hline \multirow[t]{4}{*}{$\mathrm{CC}$} & $\begin{array}{l}\text { GO: } \\
0031012\end{array}$ & extracellular matrix & $\begin{array}{l}1.486 \mathrm{e}- \\
17\end{array}$ & 12 & $\begin{array}{l}\text { MMP7, MMP12, MMP10, MMP15, MMP14, MMP8, MMP13, MMP3, } \\
\text { MMP1, MMP17, MMP9, MMP11 }\end{array}$ \\
\hline & $\begin{array}{l}\text { GO: } \\
0005578\end{array}$ & proteinaceous extracellular matrix & $\begin{array}{l}4.500 \mathrm{e}- \\
15\end{array}$ & 10 & $\begin{array}{l}\text { MMP7, MMP12, MMP10, MMP8, MMP13, MMP3, MMP1, MMP17, } \\
\text { MMP9, MMP11 }\end{array}$ \\
\hline & $\begin{array}{l}\text { GO: } \\
0005615\end{array}$ & extracellular space & $\begin{array}{l}7.395 e- \\
05\end{array}$ & 6 & MMP7, MMP10, MMP13, MMP3, MMP8, MMP9 \\
\hline & $\begin{array}{l}\text { GO: } \\
0005576\end{array}$ & extracellular region & $\begin{array}{l}4.364 \mathrm{e}- \\
04\end{array}$ & 10 & $\begin{array}{l}\text { MMP10, MMP11, MMP7, MMP17, MMP8, MMP9, MMP3, MMP12, } \\
\text { MMP13, MMP1 }\end{array}$ \\
\hline \multirow[t]{11}{*}{ MF } & $\begin{array}{l}\text { GO: } \\
0004222\end{array}$ & metalloendopeptidase activity & $\begin{array}{l}5.214 \mathrm{e}- \\
25\end{array}$ & 12 & $\begin{array}{l}\text { MMP7, MMP14, MMP13, MMP1, MMP3, MMP17, MMP8, MMP9, } \\
\text { MMP12, MMP11, MMP10, MMP15 }\end{array}$ \\
\hline & $\begin{array}{l}\text { GO: } \\
0008237\end{array}$ & metallopeptidase activity & $\begin{array}{l}4.690 \mathrm{e}- \\
22\end{array}$ & 12 & $\begin{array}{l}\text { MMP7, MMP13, MMP3, MMP12, MMP10, MMP15, MMP14, MMP1, } \\
\text { MMP8, MMP17, MMP9, MMP11 }\end{array}$ \\
\hline & $\begin{array}{l}\text { GO: } \\
0004175\end{array}$ & endopeptidase activity & $\begin{array}{l}7.643 e- \\
18\end{array}$ & 12 & $\begin{array}{l}\text { MMP7, MMP12, MMP10, MMP15, MMP14, MMP8, MMP13, MMP3, } \\
\text { MMP1, MMP17, MMP9, MMP11 }\end{array}$ \\
\hline & $\begin{array}{l}\text { GO: } \\
0008233\end{array}$ & peptidase activity & $\begin{array}{l}1.534 \mathrm{e}- \\
15\end{array}$ & 12 & $\begin{array}{l}\text { MMP7, MMP12, MMP10, MMP14, MMP8, MMP17, MMP9, MMP11, } \\
\text { MMP15, MMP13, MMP3, MMP1 }\end{array}$ \\
\hline & $\begin{array}{l}\text { GO: } \\
0005509\end{array}$ & calcium ion binding & $\begin{array}{l}4.088 \mathrm{e}- \\
12\end{array}$ & 10 & $\begin{array}{l}\text { MMP12, MMP10, MMP14, MMP8, MMP17, MMP11, MMP15, MMP13, } \\
\text { MMP3, MMP1 }\end{array}$ \\
\hline & $\begin{array}{l}\text { GO: } \\
0008270\end{array}$ & zinc ion binding & $\begin{array}{l}4.449 \mathrm{e}- \\
12\end{array}$ & 12 & $\begin{array}{l}\text { MMP7, MMP12, MMP10, MMP14, MMP17, MMP15, MMP13, MMP3, } \\
\text { MMP8, MMP9, MMP11, MMP1 }\end{array}$ \\
\hline & $\begin{array}{l}\text { GO: } \\
0046914\end{array}$ & transition metal ion binding & $\begin{array}{l}4.452 \mathrm{e}- \\
11\end{array}$ & 12 & $\begin{array}{l}\text { MMP7, MMP12, MMP10, MMP14, MMP17, MMP15, MMP13, MMP3, } \\
\text { MMP8, MMP9, MMP11, MMP1 }\end{array}$ \\
\hline & $\begin{array}{l}\text { GO: } \\
0016787\end{array}$ & hydrolase activity & $\begin{array}{l}2.326 e^{-} \\
08\end{array}$ & 12 & $\begin{array}{l}\text { MMP10, MMP14, MMP15, MMP3, MMP11, MMP7, MMP12, MMP17, } \\
\text { MMP13, MMP8, MMP9, MMP1 }\end{array}$ \\
\hline & $\begin{array}{l}\text { GO: } \\
0046872\end{array}$ & metal ion binding & $\begin{array}{l}7.714 \mathrm{e}- \\
06\end{array}$ & 12 & $\begin{array}{l}\text { MMP10, MMP14, MMP15, MMP3, MMP11, MMP7, MMP12, MMP17, } \\
\text { MMP13, MMP8, MMP9, MMP1 }\end{array}$ \\
\hline & $\begin{array}{l}\text { GO: } \\
0043169\end{array}$ & cation binding & $\begin{array}{l}9.747 \text { - } \\
06\end{array}$ & 12 & $\begin{array}{l}\text { MMP10, MMP11, MMP7, MMP17, MMP8, MMP9, MMP14, MMP15, } \\
\text { MMP3, MMP12, MMP13, MMP1 }\end{array}$ \\
\hline & $\begin{array}{l}\text { GO: } \\
0003824\end{array}$ & catalytic activity & $\begin{array}{l}1.878 \mathrm{e}- \\
04\end{array}$ & 12 & $\begin{array}{l}\text { MMP10, MMP11, MMP7, MMP17, MMP8, MMP9, MMP14, MMP15, } \\
\text { MMP3, MMP12, MMP13, MMP1 }\end{array}$ \\
\hline
\end{tabular}


Table 4 The enriched KEGG (Kyoto Encyclopedia of Genes and Genomes) pathways for MMP-related DEGs

\begin{tabular}{lllll}
\hline Pathway ID & Description & Count & Genes & $P$ Value \\
\hline hsa05219 & Bladder cancer & 2 & MMP1, MMP9 & $3.863 \mathrm{e}-05$ \\
hsa05323 & Rheumatoid arthritis & 2 & MMP3, MMP1 & $3.837 \mathrm{e}-04$
\end{tabular}

and 46 upregulated DE-miRNAs) between nonmetastatic tumour and normal samples ( $\mathrm{P}$ vs N), 50 significantly dysregulated miRNAs (33 downregulated and 18 upregulated DE-miRNAs) between metastatic tumour and normal samples (M vs $\mathrm{N})$, and 7 significantly dysregulated miRNAs (6 downregulated and 1 upregulated DE-

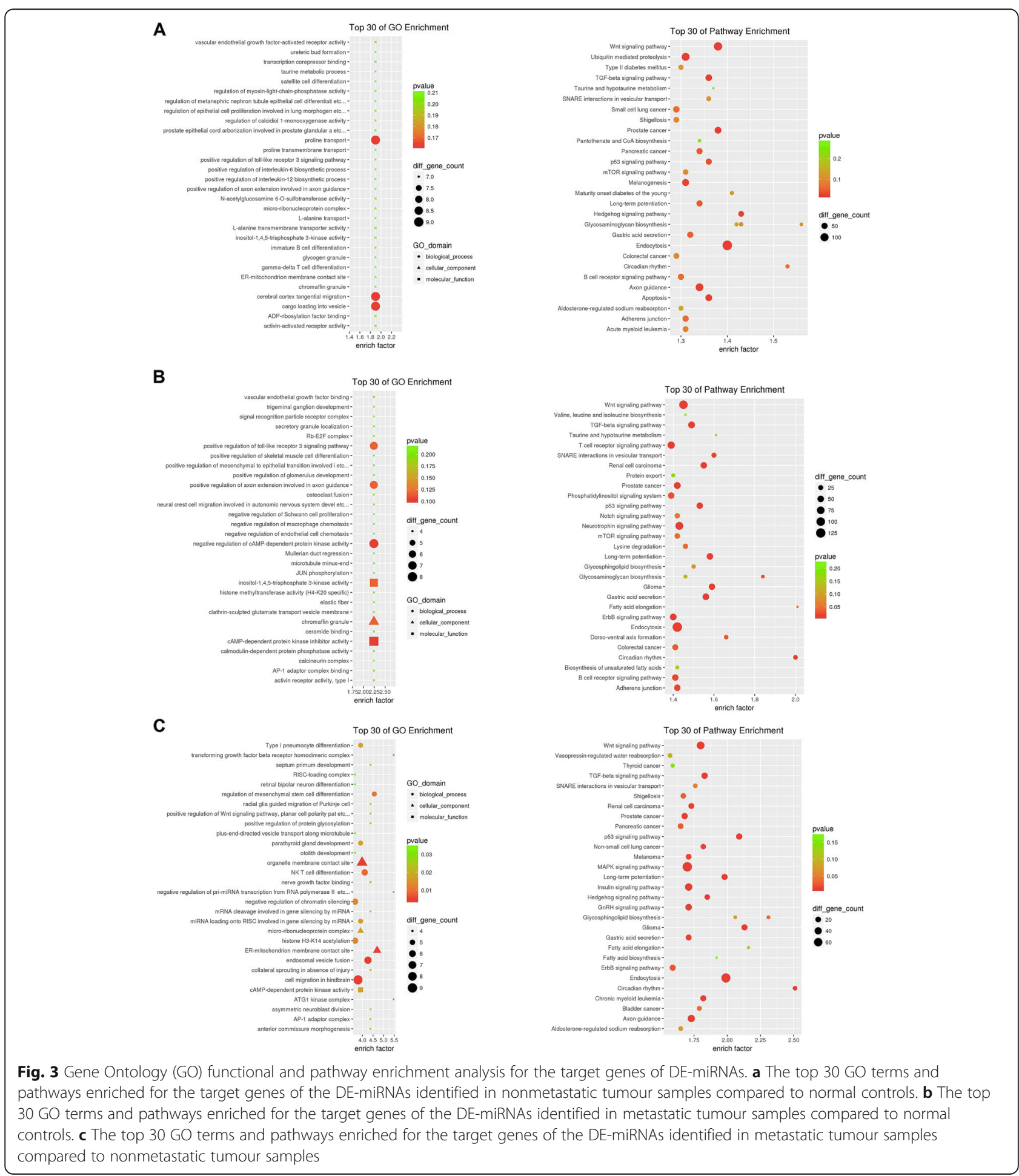




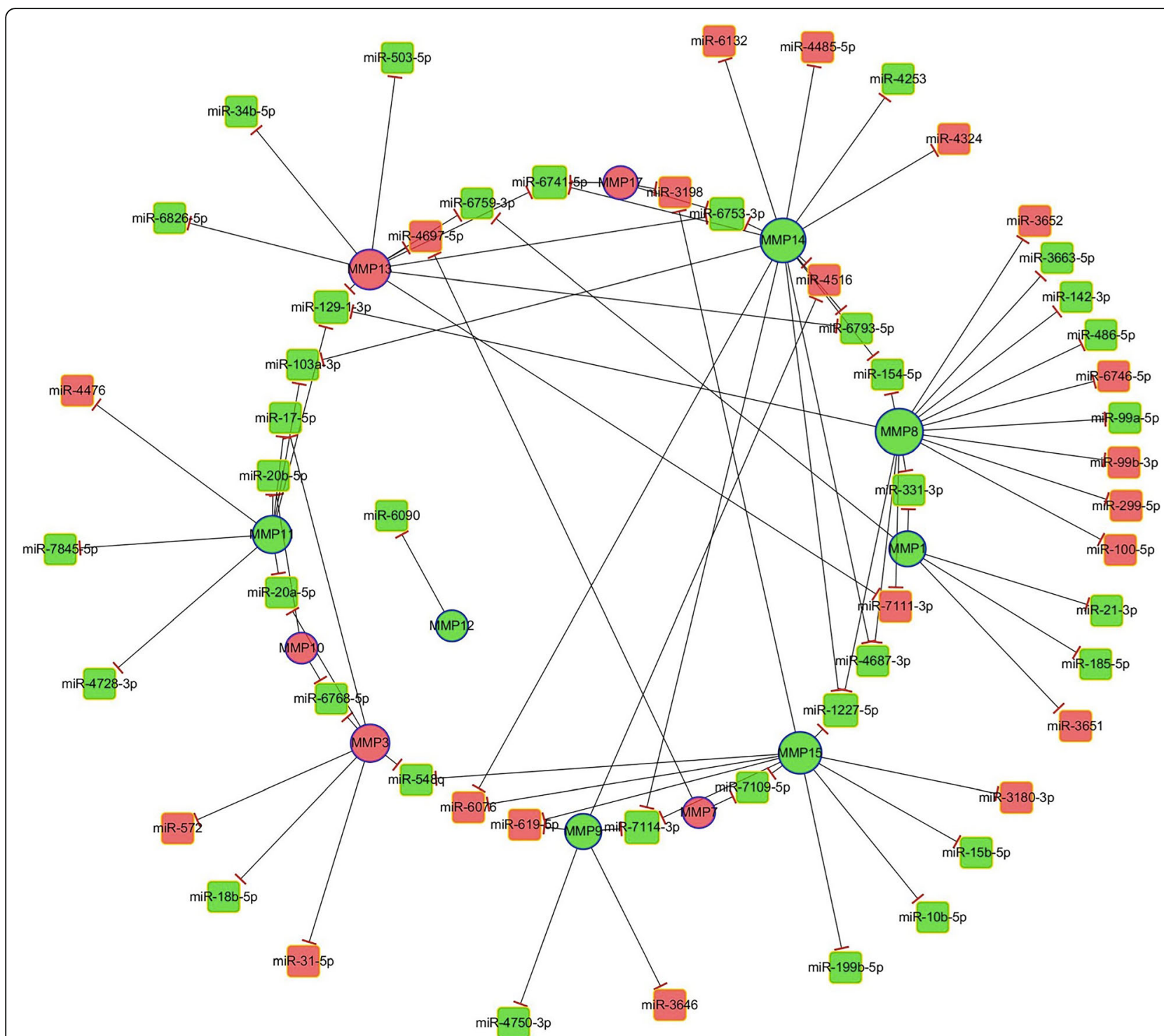

Fig. 4 The constructed MMP-related regulatory network. Red nodes represent the upregulated MMP-related DEGs or DE-miRNAs. Green nodes represent the downregulated MMP-related DEGs or DE-miRNAs. Round nodes represent the MMP-related DEGs, and square nodes represent the DE-miRNAs. Lines indicate the regulatory interactions between the MMP-related DEGs and DE-miRNAs

miRNAs) between metastatic and nonmetastatic tumour samples ( $M$ vs $P$ ) (Fig. 2a). Hierarchical clustering showed obvious miRNA expression differences among nonmetastatic tumour samples, metastatic tumour samples, and normal tissues (Fig. 2b).

\section{Functional and pathway enrichment analysis}

Functional enrichment analysis of the MMP-related DEGs revealed that these genes were notably involved with 38,4 and $11 \mathrm{GO}$ terms in the $\mathrm{BP}, \mathrm{CC}$ and MF categories, respectively (Table 3). These functions were mainly involved in the collagen catabolic process $(P<0.0001)$, extracellular matrix disassembly $(P<0.0001)$, extracellular matrix $(P<$ $0.0001)$, and metalloendopeptidase activity $(P<0.0001)$.
The three significantly enriched KEGG pathways were bladder cancer, rheumatoid arthritis and pathways in cancer (Table 4).

The target genes of the three comparison groups of differentially expressed miRNAs were also used to perform functional and pathway enrichment analysis. The target genes of the DE-miRNAs identified in nonmetastatic tumour samples compared to normal controls were mainly enriched in proline transport, cerebral cortex tangential migration, cargo loading into vesicles and endocytosis (Fig. 3a). The target genes of the DEmiRNAs identified in metastatic tumour samples compared to normal controls were mainly enriched in the negative regulation of cAMP-dependent protein kinase 
Table 5 The MMP-related DEGs and DE-miRNAs in the constructed regulatory network

\begin{tabular}{|c|c|c|}
\hline $\begin{array}{l}\text { MMP-related } \\
\text { DEGs }\end{array}$ & Degree & DE-miRNAs \\
\hline MMP12 & 1 & miR-6090 \\
\hline MMP10 & 2 & miR-20b-5p, miR-6768-5p \\
\hline MMP7 & 2 & miR-4697-5p, miR-7109-5p \\
\hline MMP17 & 3 & miR-3198, miR-6741-5p, miR-6753-3p \\
\hline MMP1 & 5 & miR-21-3p, miR-6759-3p, miR-185-5p, miR-331-3p, miR-3651 \\
\hline MMP9 & 5 & miR-619-5p, miR-3646, miR-4750-3p, miR-4516, miR-7114-3p \\
\hline MMP3 & 7 & miR-20a-5p, miR-31-5p, miR-17-5, miR-18b-5p, miR-572, miR-6768-5p, miR-548q \\
\hline MMP11 & 8 & miR-20a-5p, miR-17-5p, miR-103a-3p, miR-4728-3p, miR-20b-5p, miR-7845-5p, miR-129-1-3p, miR-4476 \\
\hline MMP13 & 10 & $\begin{array}{l}\text { miR-4697-5p, miR-6826-5p, miR-6741-5p, miR-6793-5p, miR-34b-5p, miR-6759-3p, miR-503-5p, miR-6753-3p, miR-7111-3p, } \\
\text { miR-129-1-3p }\end{array}$ \\
\hline MMP15 & 11 & $\begin{array}{l}\text { miR-619-5p, miR-3198, miR-3180-3p, miR-15b-5p, miR-7109-5p, miR-10b-5p, miR-199b-5p, miR-1227-5p, miR-6076, miR-548q, } \\
\text { miR-7114-3p }\end{array}$ \\
\hline MMP14 & 14 & $\begin{array}{l}\text { miR-6132, miR-4485-5pmiR-103a-3pmiR-6741-5p, miR-6793-5p, miR-4253, miR-154-5p, miR-1227-5p, miR-6753-3p, miR-4324, } \\
\text { miR-6076, miR-4516, miR-7114-3p, miR-4687-3p }\end{array}$ \\
\hline MMP8 & 15 & $\begin{array}{l}\text { miR-3652, miR-3663-5p, miR-142-3p, miR-486-5p, miR-6746-5p, miR-99a-5p, miR-331-3p, miR-154-5p, miR-99b-3p, miR-299- } \\
\text { 5p, miR-1227-5p, miR-7111-3p, miR-129-1-3p, miR-4687-3p, miR-100-5p }\end{array}$ \\
\hline
\end{tabular}

Note: the miRNA names in red color are validated using qRT-PCR

activity, cAMP-dependent protein kinase inhibitor activity, and endocytosis (Fig. 3b). The target genes of the DE-miRNAs identified in metastatic tumour samples compared to nonmetastatic tumour samples were mainly enriched in organelle membrane contact site, cell migration in hindbrain, Wnt signalling pathway, TGF-beta signalling pathway, MAPK signalling pathway, and endocytosis (Fig. 3c).

\section{Construction of the MMP-related regulatory network}

The target genes of the DE-miRNAs were predicted, and the relationships related to MMPs were selected for regulatory network construction. The regulatory network involved 55 DE-miRNAs and 12 MMP-related DEGs (Fig. 4). MMP7 was regulated by miR-4697-5p and miR-7109-5p. MMP13 was regulated by $10 \mathrm{DE}-$ miRNAs (miR-4697-5p, miR-6826-5p, miR-6741-5p, miR-6793-5p, miR-34b, miR-6759-3p, miR-503-5p, miR6753-3p, miR-7111-3p, and miR-129-1-3p). MMP10 was the target gene of miR-20b-5p and miR-6768-5p. $M M P 12$ was regulated by miR-6090, and MMP9 was regulated by 5 DE-miRNAs (miR-619-5p, miR-3646, miR-4750-3p, miR-4516, and miR-7114-3p) (Table 5).

\section{Validation by data mining and qRT-PCR}

The expression levels of MMP7 $(P<0.0001)$, MMP13 $(P<0.0001)$ and MMP10 $(P<0.0001)$ were also significantly higher in OSCC samples than in normal samples by data mining of published profiles in Oncomine (http://www.oncomine.org) (Fig. 5a). The expression levels of MMP7, MMP13, MMP10, miR-7109-5p and miR-34b in nonmetastatic cancer samples and metastatic cancer samples were measured by qRT-PCR. The expression levels of MMP7 $(P=0.0123)$ and MMP13 $(P=$ $0.0147)$ were significantly increased in the metastatic tumour samples, while that of MMP10 $(P=0.0932)$ was not (Fig. 5b). The expression levels of both miR-7109-5p $(P=0.0233)$ and miR-34b $(P=0.0146)$ were decreased in metastatic tumour samples compared with nonmetastatic tumour samples (Fig. 5c).

\section{Discussion}

In our study, mRNA and miRNA microarrays were used to analyse the expression profiles of MMPs and miRNAs in nonmetastatic tumour samples, metastatic tumour samples, and normal tissues. The results showed that 10 MMP genes were upregulated and MMP27 was downregulated in nonmetastatic tumour samples compared with normal controls. MMP12, MMP1, MMP9, MMP7, $M M P 3, M M P 14, M M P 17, M M P 13$, and $M M P 10$ were the 9 common upregulated genes in metastatic and nonmetastatic tumour samples compared with the normal controls. Moreover, MMP7, MMP13, and MMP10 were significantly upregulated in metastatic tumour samples compared with nonmetastatic tumour samples.

Deraz et al. [32] revealed that the overexpression of MMP-10 could promote the invasion and metastasis of head and neck squamous cell carcinoma, and invasion driven by MMP-10 is possibly associated with p38 MAPK inhibition. It has been reported that MMP-13 could promote the invasion, migration, and adhesion abilities of oral cancer cells [33]. The abnormal expression of MMP-7 has been found to be closely related to the biological behaviour of OSCC, and MMP-7 may be 


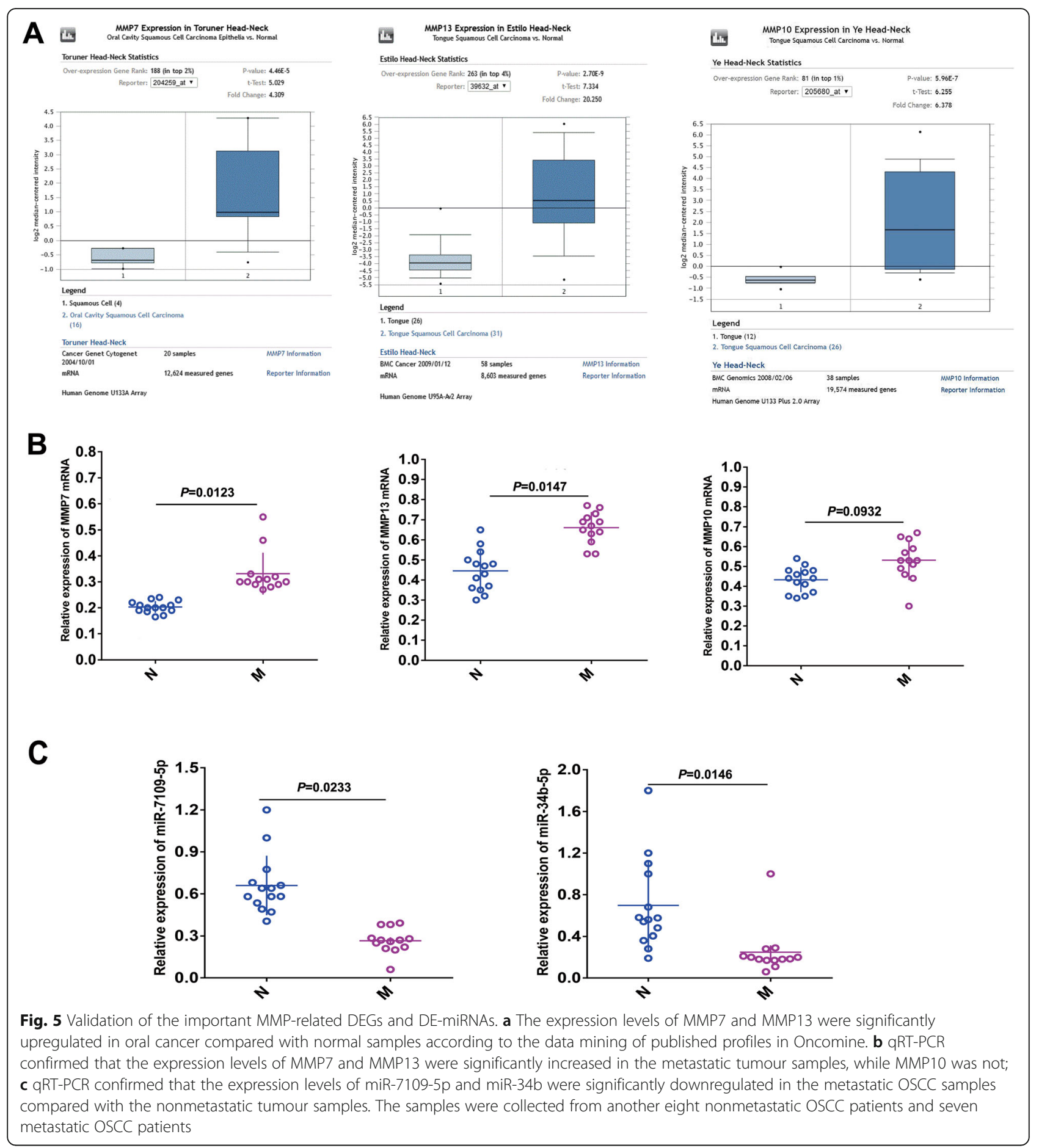

induced by COX-2 to contribute to the invasion and metastasis of OSCC [34]. The upregulation of glutamate decarboxylase 1 (GAD1) correlated with cellular invasiveness and migration in OSCC by regulating $\beta$-catenin translocation and MMP7 activation [35]. Functional enrichment analysis revealed that $M M P 7, M M P 13$, and $M M P 10$ were related to the collagen catabolic process, extracellular matrix disassembly, extracellular matrix, and metalloendopeptidase activity. Therefore, the overexpression of MMP7, MMP13, and MMP10 might play important roles in controlling tumoural invasiveness and metastasis in OSCC.

The expression levels of MMP7, MMP13 and MMP10 were validated to be significantly upregulated in oral cancer compared with normal samples according to the data mining of published profiles in Oncomine. Among 
these differentially expressed MMPs, we focused on the roles of MMP7, MMP13 and MMP10. After the target genes of the DE-miRNAs were predicted, functional enrichment analysis showed that the target genes of the DE-miRNAs identified in metastatic tumour samples compared to nonmetastatic tumour samples were mainly enriched in organelle membrane contact sites, cell migration in the hindbrain, and the TGF-beta signalling pathway. TGF- $\beta 1$-triggered epithelial-mesenchymal transition (EMT) may play important roles in OSCC progression by upregulating MMPs to promote EMT [36]. Thus, the identified DE-miRNAs might be important for the progression of OSCC by regulating the target gene levels to influence the TGF-beta signalling pathway.

In our study, the regulatory relationships related to MMPs were selected to construct a regulatory network. In the regulatory network, $M M P 7$ was regulated by miR4697-5p and miR-7109-5p. MMP13 was regulated by 10 DE-miRNAs (miR-4697-5p, miR-6826-5p, miR-6741-5p, miR-6793-5p, miR-34b, miR-6759-3p, miR-503-5p, miR6753-3p, miR-7111-3p, and miR-129-1-3p). Moreover, qRT-PCR confirmed that the expression of miR-7109-5p and miR-34b was significantly downregulated in metastatic OSCC samples compared with nonmetastatic tumour samples using samples collected from another cohort of OSCC patients. The abnormal expression of miR-7109-5p has been reported to occur in breast cancer and is associated with cancer development in patients with chronic obstructive pulmonary disease [37, 38]. The reduced expression of miR-34b and miR-129$3 p$ was observed in gastric cancers due to DNA hypermethylation and was associated with poor clinicopathological features [39]. It was also suggested that the reduced expression of miR-34b*/c may be particularly important for the progression to the most advanced stages of human epithelial ovarian cancer [40]. Low expression levels of miR-34b and miR-34c were associated with distant metastasis formation in lung cancer [41]. To our knowledge, few studies have reported the regulatory mechanisms of miR-7109-5p and miR-34b in OSCC. According to the results of our study, miR-7109$5 \mathrm{p}$ and miR-34b seem to have tumour suppressor functions in OSCC. The aggressive form of OSCC shows the downregulation of these two miRNAs and subsequent upregulation of MMP 7 and MMP13, which are normally inhibited by miR-7109-5p and miR-34b. The feasibility of miR-7109-5p and miR-34b as promising prognostic and diagnostic indicators or potential cancer therapeutic targets will be evaluated in further studies. In the future, we will focus on the interaction of miRNAs and MMPs and the mechanism of OSCC progression mediated by the miRNA axis to provide valuable strategies for the diagnosis, treatment and prognosis of OSCC.
Several limitations of this study should be addressed. The most important limitation in this regard is the limited number of study samples and inability to control for potential confounders. Another limitation is that the patients included in this study had varying $\mathrm{T}$ and $\mathrm{N}$ stages, and the two groups of cases were not selected in pairs. The homogeneity of the two groups of cases was different. The metastatic group appears to be more homogeneous than the nonmetastatic group. The results of this study are at the transcriptional level, and further experiments at the protein level are needed to verify the results of this experiment.

\section{Conclusion}

In conclusion, our study performed gene and miRNA microarray analysis to reveal the underlying regulatory mechanisms of miRNAs and MMPs involved in the OSCC metastatic process. The MMP-related DEGs and DE-miRNAs were identified among the nonmetastatic tumour samples, metastatic tumour samples, and normal tissues. $M M P 7, M M P 13$, and $M M P 10$ were upregulated in metastatic tumours compared with nonmetastatic tumours. The reduced expression of miR-7109-5p and miR-34b might play important roles in the metastasis of OSCC by upregulating $M M P 7$ and $M M P 13$, respectively.

\section{Supplementary information}

Supplementary information accompanies this paper at https://doi.org/10. 1186/s12903-020-1013-0.

Additional file 1: The raw data of Microarray analysis.

\section{Abbreviations}

AJCC/ UICC: American Joint Committee on Cancer/Union for International Cancer Control; DEGs: Differentially expressed genes; DE-

miRNAs: Differentially expressed miRNAs; ECM: Extracellular matrix; EMT: Epithelial-mesenchymal transition; miRNAs: MicroRNAs; MMPs: Matrix metalloproteinases; OSCC: Oral squamous cell carcinoma

\section{Acknowledgements}

Not applicable.

\section{Authors' contributions}

ZHR and WC developed the design of this study. ZHR and KW performed the clinical examination and contributed to the analysis of data. YR and ZQL supervised the data assessment. KW, YR, and ZQL performed statistical analyses, and all authors contributed to the interpretation of the data. ZHR, KW, and WC drafted the manuscript. All authors read and approved the final manuscript.

\section{Funding}

This study was supported by the SHIPM-mu fund No. JC201902 from the Shanghai Institute of Precision Medicine, Ninth People's Hospital Shanghai Jiao Tong University School of Medicine, which provided economic support for our study in its previous research design; The Interdisciplinary Program of Shanghai Jiao Tong University (ZH2018QNA08), which provided economic support for our study in its data collection; the Shanghai Anticancer Association EYAS PROJECT (SACA-CY1B06), which provided economic support for our study in its analysis and interpretation of data; and The National Natural Science Foundation of China $(81672745,81972589)$, which provided economic support for our study in its writing the manuscript. 


\section{Availability of data and materials}

The datasets used during the current study are available from supplementary file.

\section{Ethics approval and consent to participate}

This study was approved by the Scientific Research Projects Approval Determination of Independent Ethics Committee of Shanghai Ninth People's Hospital affiliated with Shanghai Jiao Tong University. Informed consent (written) was obtained from all patients before the samples were collected during surgery.

\section{Consent for publication}

The patients signed an informed consent form agreeing with the publication of this study.

\section{Competing interests}

The authors declare that they have no competing interests.

Received: 19 July 2019 Accepted: 17 January 2020

Published online: 29 January 2020

\section{References}

1. Chen W, Zheng R, Zuo T, Zeng H, Zhang S, He J. National cancer incidence and mortality in China, 2012. Chin J Cancer Res. 2016;28(1):1-11.

2. Siegel RL, Miller KD, Jemal A. Cancer statistics, 2017. CA Cancer J Clin. 2017; 67(1):7-30.

3. Severino P, Oliveira LS, Andreghetto FM, Torres N, Curioni O, Cury PM, Toporcov TN, Paschoal AR, Durham AM. Small RNAs in metastatic and nonmetastatic oral squamous cell carcinoma. BMC Med Genet. 2015;8(1):1-15.

4. Lin CW, Yang WE, Lee WJ, Hua KT, Hsieh FK, Hsiao M, Chen CC, Chow JM, Chen MK, Yang SF, et al. Lipocalin 2 prevents oral cancer metastasis through carbonic anhydrase IX inhibition and is associated with favourable prognosis. Carcinogenesis. 2016;37(7):712-22.

5. Ren ZH, Xu JL, Li B, Fan TF, Ji T, Zhang CP. Elective versus therapeutic neck dissection in node-negative oral cancer: evidence from five randomized controlled trials. Oral Oncol. 2015;51(11):976-81.

6. Ren ZH, Gong ZJ, Wu HJ. Unit resection of buccal squamous cell carcinoma: description of a new surgical technique. Oncotarget. 2017;8(32):52420-31.

7. Munchow EA, Bottino MC. Recent advances in adhesive bonding - the role of biomolecules, Nanocompounds, and bonding strategies in enhancing resin bonding to dental substrates. Curr Oral Health Rep. 2017;4(3):215-27.

8. Murphy G, Nagase H. Progress in matrix metalloproteinase research. Mol Asp Med. 2008;29(5):290-308.

9. Gomis-Ruth FX. Catalytic domain architecture of metzincin metalloproteases. J Biol Chem. 2009;284(23):15353-7.

10. Blanco-Prieto S, Barcia-Castro L, Paez de la Cadena M, Rodriguez-Berrocal FJ, Vazquez-Iglesias L, Botana-Rial Ml, Fernandez-Villar A, De Chiara L. Relevance of matrix metalloproteases in non-small cell lung cancer diagnosis. BMC Cancer. 2017;17(1):823.

11. Moro N, Mauch C, Zigrino P. Metalloproteinases in melanoma. Eur J Cell Biol. 2014;93(1-2):23-9.

12. Fouad YA, Aanei C. Revisiting the hallmarks of cancer. Am J Cancer Res. 2017;7(5):1016-36.

13. de Vicente JC, Fresno MF, Villalain L, Vega JA, Hernández VG. Expression and clinical significance of matrix metalloproteinase-2 and matrix metalloproteinase-9 in oral squamous cell carcinoma. Oral Oncol. 2005;41(3): 283-93.

14. Eccles SA. Expression of matrix metalloproteinases and their inhibitors correlates with invasion and metastasis in squamous cell carcinoma of the head and neck. Arch Otolaryngol Head Neck Surg. 2001;127(7):813.

15. Yu T, Wu Y, Helman JI, Wen Y, Wang C, Li L. CXCR4 promotes oral squamous cell carcinoma migration and invasion through inducing expression of MMP-9 and MMP-13 via the ERK signaling pathway. Mol Cancer Res. 2011;9(2):161.

16. Bartel DP. MicroRNAs: target recognition and regulatory functions. Cell. 2009:136(2):215-33.

17. Chekulaeva M, Filipowicz W. Mechanisms of miRNA-mediated posttranscriptional regulation in animal cells. Curr Opin Cell Biol. 2009;21(3): 452-60.

18. Liu X, Yu J, Jiang L, Wang A, Shi F, Ye H, Zhou X. MicroRNA-222 regulates cell invasion by targeting matrix metalloproteinase 1 (MMP1) and manganese superoxide dismutase 2 (SOD2) in tongue squamous cell carcinoma cell lines. Cancer Genomics Proteomics. 2009;6(3):131-9.

19. Le L, Xiaofeng $X$, Jing L, Yang G, Zhenghui X, Haiping Z, Wei J, Weijian S, Qiaoming Z. MicroRNA-29a upregulates MMP2 in oral squamous cell carcinoma to promote cancer invasion and anti-apoptosis. Biomed Pharmacother. 2014;68(1):13-9.

20. Amin MB, Greene FL, Edge SB, Compton CC, Gershenwald JE, Brookland RK, Meyer L, Gress DM, Byrd DR, Winchester DP. The eighth edition AJCC Cancer staging manual: continuing to build a bridge from a populationbased to a more "personalized" approach to cancer staging. CA Cancer J Clin. 2017:67(2):93-9.

21. Fan T, Chen J, Zhang L, Gao P, Hui Y, Xu P, Zhang X, Liu H. Bit1 knockdown contributes to growth suppression as well as the decreases of migration and invasion abilities in esophageal squamous cell carcinoma via suppressing FAK-paxillin pathway. Mol Cancer. 2016;15:23.

22. Ritchie ME, Phipson B, Wu D, Hu Y, Law CW, Shi W, Smyth GK. Limma powers differential expression analyses for RNA-sequencing and microarray studies. Nucleic Acids Res. 2015;43(7):e47.

23. Wang L, Cao C, Ma Q, Zeng Q, Wang H, Cheng Z, Zhu G, Qi J, Ma H, Nian $\mathrm{H}$, et al. RNA-seq analyses of multiple meristems of soybean: novel and alternative transcripts, evolutionary and functional implications. BMC Plant Biol. 2014;14:169.

24. Gosling C. Encyclopedia of distances. Ref Rev. 2009;24(6):1-583.

25. Agarwal V, Bell GW, Nam JW, Bartel DP. Predicting effective microRNA target sites in mammalian mRNAs. Elife Sciences. 2015:4:e05005.

26. Wong $N$, Wang $X$. miRDB: an online resource for microRNA target prediction and functional annotations. Nucleic Acids Res. 2014:43(D1):D146-52.

27. Sheng-Da H, Feng-Mao L, Wei-Yun W, Chao L, Wei-Chih H, Wen-Ling C, Wen-Ting T, Goun-Zhou C, Chia-Jung L, Chih-Min C. miRTarBase: a database curates experimentally validated microRNA-target interactions. Nucleic Acids Res. 2011;39(Database issue):D163.

28. Sethupathy P, Corda BHatzigeorgiou AG. TarBase: a comprehensive database of experimentally supported animal microRNA targets. RNA. 2006; 12(2):192-7.

29. Shannon P, Markiel A, Ozier O, Baliga NS, Wang JT, Ramage D, Amin N, Schwikowski B, Ideker T. Cytoscape: a software environment for integrated models of biomolecular interaction networks. Genome Res. 2003;13(11): 2498-504.

30. Huang DW, Sherman BT, Tan Q, Collins JR, Alvord WG, Roayaei J, Stephens R, Baseler MW, Lane HC, Lempicki RA. The DAVID gene functional classification tool: a novel biological module-centric algorithm to functionally analyze large gene lists. Genome Biol. 2007;8(9):R183.

31. Wu J, Mao X, Cai T, Luo J, Wei L. KOBAS server: a web-based platform for automated annotation and pathway identification. Nucleic Acids Res. 2006; 34(Web Server issue):W720-4.

32. Deraz EM, Kudo Y, Yoshida M, Obayashi M, Tsunematsu T, Tani H, Siriwardena SB, Keikhaee MR, Qi G, lizuka S, et al. MMP-10/stromelysin-2 promotes invasion of head and neck cancer. PLoS One. 2011;6(10):e25438.

33. Huang SH, Law CH, Kuo PH, Hu RY, Yang CC, Chung TW, Li JM, Lin LH, Liu YC, Liao EC, et al. MMP-13 is involved in oral cancer cell metastasis. Oncotarget. 2016;7(13):17144-61.

34. Li T-J, Cui J. COX-2, MMP-7 expression in oral lichen planus and ora squamous cell carcinoma. Asian Pac J Trop Med. 2013;6(8):640-3.

35. Kimura R, Kasamatsu A, Koyama T, Fukumoto C, Kouzu Y, Higo M, EndoSakamoto Y, Ogawara K, Shiiba M, Tanzawa H, et al. Glutamate acid decarboxylase 1 promotes metastasis of human oral cancer by $\beta$-catenin translocation and MMP7 activation. BMC Cancer. 2013;13(1):555.

36. Qiao B, Johnson NW, Gao J. Epithelial-mesenchymal transition in oral squamous cell carcinoma triggered by transforming growth factor-beta1 is snail family-dependent and correlates with matrix metalloproteinase-2 and -9 expressions. Int J Oncol. 2010;37(3):663.

37. Keller A, Fehlmann T, Ludwig N, Kahraman M, Laufer T, Backes C, Vogelmeier C, Diener C, Biertz F, Herr C, et al. Genome-wide MicroRNA expression profiles in COPD: early predictors for Cancer development. Genomics Proteomics Bioinformatics. 2018;16(3):162-71.

38. Kumar SGS, Kumar $\vee$, et al. Identification of key miRNA biomarkers by miRNA-gene interactions network regulating breast cancer in human. Asian J Pharm Pharmacol. 2018;4(5):608-14.

39. Tsai K-W, Wu C-W, Hu L-Y, Li S-C, Liao Y-L, Lai C-H, Kao H-W, Fang W-L, Huang $\mathrm{K}-\mathrm{H}$, Chan W-C, et al. Epigenetic regulation of miR-34b and miR-129 expression in gastric cancer. Int J Cancer. 2011;129(11):2600-10. 
40. Corney DC, Hwang Cl, Matoso A, Vogt M, Flesken-Nikitin A, Godwin AK, Kamat AA, Sood AK, Ellenson LH, Hermeking H, Nikitin AY. Frequent downregulation of miR-34 family in human ovarian cancers. Clin Cancer Res. 2010;16(4):1119-28.

41. Daugaard I, Knudsen A, Kjeldsen TE, Hager H, Hansen LL. The association between miR-34 dysregulation and distant metastases formation in lung adenocarcinoma. Exp Mol Pathol. 2017;102(3):484-91.

\section{Publisher's Note}

Springer Nature remains neutral with regard to jurisdictional claims in published maps and institutional affiliations.

Ready to submit your research? Choose BMC and benefit from:

- fast, convenient online submission

- thorough peer review by experienced researchers in your field

- rapid publication on acceptance

- support for research data, including large and complex data types

- gold Open Access which fosters wider collaboration and increased citations

- maximum visibility for your research: over $100 \mathrm{M}$ website views per year

At BMC, research is always in progress.

Learn more biomedcentral.com/submissions 